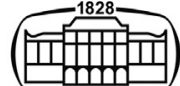

AKADÉMIAI KIADÓ

\title{
Developing migrants prototypes performance through bottom-up construction method
}

\author{
Rojhat Ibrahim $^{1,2 *} \odot$ and Bálint Baranyai ${ }^{3}$
}

\section{Pollack Periodica • \\ An International Journal \\ for Engineering and Information Sciences}

16 (2021) 3, 127-132

DOI:

10.1556/606.2021.00392

(c) 2021 The Author(s)

\author{
${ }^{1}$ Marcel Breuer Doctoral School, Faculty of Engineering and Information Technology, Boszorkány u. \\ 2 and Energia Design Building Technology Research Group, Szentágothai Research Centre, \\ University of Pécs, Ifjúság útja 20, H-7624, Pécs, Hungary \\ ${ }^{2}$ Department of Architecture, Faculty of Engineering, University of Duhok, Iraq \\ ${ }^{3}$ Department of Building Structures and Energy Design, Institute of Architecture, Faculty of \\ Engineering and Information Technology, Boszorkány u. 2 and Energia Design Building Technology \\ Research Group, Szentágothai Research Centre, University of Pécs, Ifjúság útja 20, H-7624, Pécs, \\ Hungary
}

Received: January 6, 2021 • Revised manuscript received: April 21, 2021 • Accepted: May 17, 2021

Published online: August 11, 2021
ORIGINAL RESEARCH PAPER

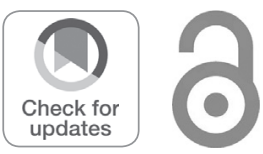

* Corresponding author. E-mail: rojhatbarwary@yahoo.com

\begin{abstract}
Natural and man-made disasters are vital issues that led to the increasing number of migrants, many of them stayed displaced for decades this requires more permanent dwellings. The main aim of the study is to investigate the impact of the bottom-up construction method on developing migrant's shelters energy and thermal comfort performance. Dynamic simulation tool Indoor Climate and Energy (IDA ICE 4.8) has been used to assess nine different scenarios. The results quantified that the annually delivered energy and thermal comfort accepted hours of proposed scenario nine (S9) is better compared to base-case scenario one (S1) by $63 \% \mathrm{kWh}$ and 4,215 h respectively. Methodologies and results of this paper can be adopted and applied for various places of the world affected by migration issue.
\end{abstract}

\section{KEYWORDS}

post-disaster shelters, energy consumption, affordable and adaptable strategies, low impact materials, delivered energy, thermal comfort

\section{INTRODUCTION}

International Organization for Migration (IOM) stated that the term migrant including any people who have displaced within or outside their own country [1]. United Nations High Commissioner for Refugees (UNHCR) declared that at the end of 2019 the number of displaced people worldwide is 79.5 million [2]. In Iraq, the displacement situation is one of the world most unstable and critical that is due to several reasons for instance ethnic and religious persecution, internal armed conflict, external intervention, political situation and natural disasters [3]. Similarly in the Kurdistan Region of Iraq (KRI) geopolitical factor and the strategic location near the border of Syria, Turkey and Iran made the people live the displaced issue either to be refugees or host them. Board of Relief and Humanitarian Affairs (BRHA) in Duhok city North of Iraq quantified that there are 616,625 Internal Displaced People (IDP) and refugees live simply in Duhok [4].

Many migrants live displaced for decades globally, for instance, it has been more than three decades that both Senegalese and Somalian refugees displaced to the Gambia and Kenya respectively [5, 6]. Moreover, from 2011 till now, Kurdish from Syria live as refugees in KRI [7]. The majority of migrants live in inefficient and uncomfortable transitional and temporary shelters this normally carries a high burden on the environment and host countries and cost billions of dollars for establishing due to the short lifespan of that shelters $[8,9]$. 
Currently, all advanced countries focused on building energy problems in different ways to use energy rationally and to preserve it is sources [10]. The building sector has consumed $40 \%$ of total energy and natural resources likewise it is the main source of about $40-70 \%$ of $\mathrm{CO}_{2}$ emissions globally [11-13]. Although fossil fuel is a prevalent source of energy in KRI by $85 \%$ [14] however, there is still a shortage in supplied electricity for instance, Duhok City in 2018 has simply $13 \mathrm{~h}$ per day from the national electricity [15]. Zebari et al. [16] and Ibrahim et al. [17] stated that due to inappropriate building design in KRI mechanical systems for example, split units are commonly used and in some instances, every single room has installed one.

Halliday et al. [18] demonstrated that Low Impact Constructions (LIC) comprise approaches to ecological design. LIC is based on the use of locally sourced, traditional and natural materials besides, locally labors skills and collaborative work moreover, extremely cost-effective furthermore, minimum impact on the site and environment $[18,19]$. LIC includes both top-down solutions (prefabricated) and bottom-up solutions to be built on-site by the local workers or migrants using available local materials and could be managed by local authorities or NonGovernmental Organizations (NGOs) [20].

Several studies have investigated various strategies in an attempt to enhance the quality of migrant's dwellings worldwide, for instance, Dabaieh and Andriasyan [9] discussed a proposal for reusing and rehabilitating vernacular settlements for migrants in the context of the Middle East. Wagemann [21] investigated in research titled From Shelter to Home different strategies for flexibility in post-disaster accommodation through movable buildings, design and construction methods. Rincon et al. [22] analyzed and simulated the thermal behavior of dome shape earth-bag building in the Mediterranean climate in the same way, another study assessed the carbon impact of migrants shelters and resulted that using local materials like straw, wood, and clay, can extremely decrease the carbon footprint [8]. Ibrahim et al. [23] observed the superiority of the adobe dome over other humanitarian agencies shelters as tent caravans in northern Syria through analyzed and compared based simulated research. Al Ameen [24] proposed an incremental upgrading strategy on the planning and designing phases for refugee's shelters in Iraq, for instance, a wall panel composed of layers of steel mesh, tarpaulin, and sand moreover roof canopy and sunspace.

Based on the mentioned problem findings from an increasing number of displaced people, the short life-span of shelters and the environment and energy challenges, this study investigates the method that comprises more comfortable, flexible and affordable permanent shelters. Therefore, this paper aims to develop energy end thermal comfort performance for shelters through the bottom-up construction method through exploiting a set of materials on one single prototype.

\section{METHODOLOGIES}

\subsection{Conceptual framework}

Based on the four fundamentals steps to do scientific research this study has been done as it is clear in the conceptual framework flow chart in Table 1. Although the investigation started generally to follow the literature regarding migrant's shelters while in the processing step targeted aim of the research has been exposed. Then the analysis and preparing scenarios are organized for the reason of development, later the selected scenarios have been simulated to validate and assess the performance of prototypes.

\subsection{Data processing and cases studies}

The main aim of this study has been exposed in this stage after depth investigation of previous literature and BRHA conduction in Duhok. Firstly, the study investigated various refugees' shelters in terms of typologies, materials, techniques and performance. Then, several factors like affordable strategies, long life-span, adaptability, weather resistance, community involvement, and energy consumption have been considered. Finally, due to the long displacement period for many cases, the LIC materials and techniques with the bottom-up method have been targeted for this research.

The context of the study has focused on the refugees' shelters in Duhok City in KRI. Duhok City is located at the latitude of $\left(36^{\circ} 51^{\prime} 43.45^{\prime \prime} \mathrm{N}\right)$ and longitude $\left(42^{\circ} 59^{\prime} 50.30^{\prime \prime}\right.$ E) [25]. However, the Köppen-Geiger climate classification referred that Duhok city has a borderline semi-arid and

Table 1. Conceptual framework methodologies

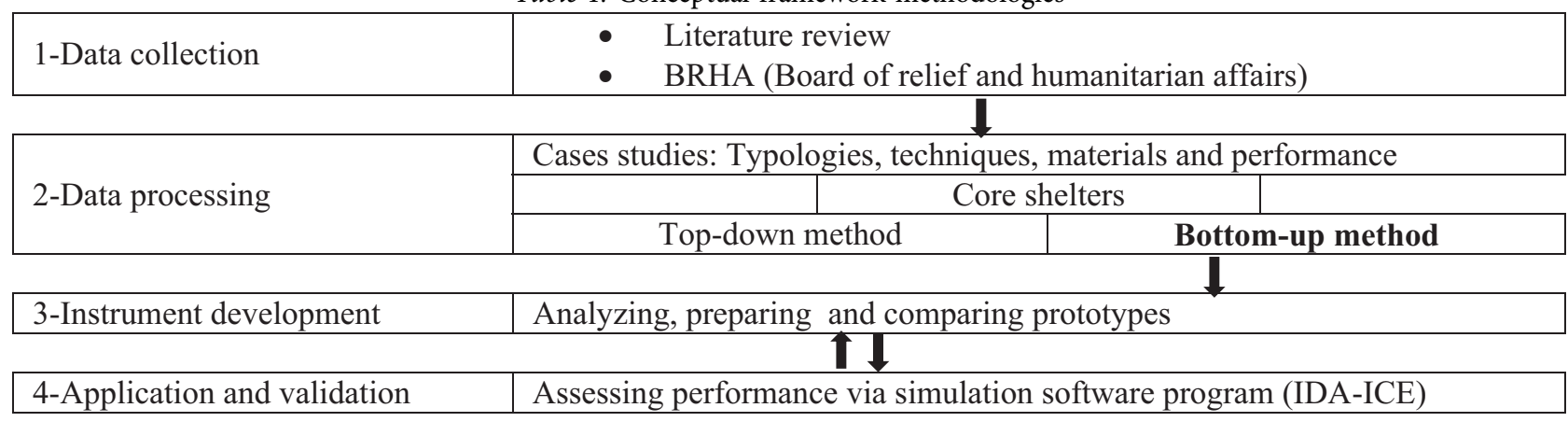




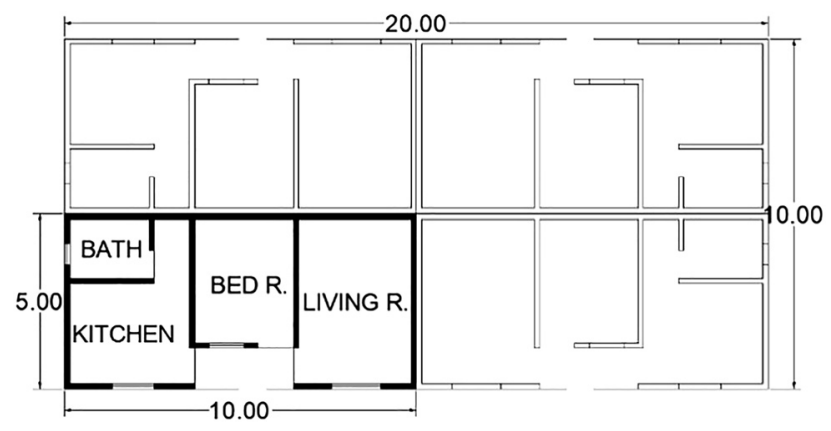

Fig. 1. Base case floor plan (Source: Author)

Mediterranean climate with extremely hot dry summers and mild to cool wet winters [26] whereas according to [27] it has been divided into various climatic zones started from very humid, semi-humid Mediterranean and semi-arid cool winter to warm and very warm summer consequently the case has been selected from Domiz camp in Duhok and has been characterized as a semi-arid cool winter and very warm summer.

The Ministry of Planning in KRI revealed that the average household size is 5.1 members in Kurdistan [28] based on that the case has been taken to host a family of five persons. The core shelter case is semi-detached in a rectilinear grid layout system as usual urban planning characters in KRI [29], with an area of $50 \mathrm{~m}^{2}(5 \mathrm{~m} \times 10 \mathrm{~m})$ and a height of $2.6 \mathrm{~m}$, it includes few spaces for instance bedroom for parents, living room to be a bedroom for three kids at night, kitchen and bath include toilet Fig. 1.

The materials which have been used are solid concrete block with a width of $15 \mathrm{~cm}$ for the walls and are plastered with rendered concrete $2 \mathrm{~cm}$, plastic doors and windows, concrete floor and zinc sheets or sandwich panels in some instances for the roof.

\subsection{Analysis and evaluation process}

To prepare the process of prototypes evaluation several procedures have been done. Firstly among divers of LIC materials and techniques, few of them have been selected like straw-bales, cob, and earth-bag for walls furthermore mixed technique wood, straw, and soil for the roof. Then the
Table 3. Prototypes scenarios and components

\begin{tabular}{lc}
\hline Scenarios & Components \\
\hline $\begin{array}{l}\text { Base model scenario } \\
\text { 1 (S1) }\end{array}$ & $\mathrm{R} 1+\mathrm{W} 1+\mathrm{F} 1+$ Window 1+Door 1 \\
Base model scenario & $\mathrm{R} 2+\mathrm{W} 1+\mathrm{F} 1+$ Window 1+Door 1 \\
2 (S2) & \\
Scenario 3 (S3) & $\mathrm{R} 3+\mathrm{W} 1+\mathrm{F} 1+$ Window 1+Door 1 \\
Scenario 4 (S4) & $\mathrm{W} 2+\mathrm{R} 1+\mathrm{F} 1+$ Window 1+Door 1 \\
Scenario 5 (S5) & $\mathrm{W} 3+\mathrm{R} 1+\mathrm{F} 1+$ Window 1+Door 1 \\
Scenario 6 (S6) & W4+R1+F1+Window 1+Door 1 \\
Scenario 7 (S7) & R1+W1+F1+Window 2+Door 2 \\
Scenario 8 (S8) & Best Roof + Best Wall+F1+Window \\
& 2+Door 2 \\
Scenario 9 (S9) & Best Roof (WSS) + Proposed \\
& variation wall (W2+W3+W4)+ \\
& F1+Window 2+Door 2 \\
\hline
\end{tabular}

physical properties of the selected materials have been reviewed to determine $U$ value (thermal transmittance) according to several resources [30-32] Table 2.

Subsequently, nine scenarios have been prepared to assess it is performing as it is clear in Table 3, first and second scenarios $(\mathrm{S} 1, \mathrm{~S} 2)$ represented base model references components. Finally, for affordability and adaptability factors and make it easy to expand shelter in the future from $50 \mathrm{~m}^{2}$ to $100 \mathrm{~m}^{2}$ and prolonged life-span few low impact materials have been proposed for one single prototype walls as it is clear in scenario nine (S9)

\subsection{Validation tool and simulation process}

As a tool of validation for assessing the energy performance and thermal comfort of nine prototypes scenarios, the dynamic simulation model titled Indoor Climate and Energy IDA ICE 4.8 software has been applied Fig. 2 .

Before running the simulation process for the whole year the scenarios have specified previous steps. Firstly, setting the south orientation for all scenarios then, the upper and lower limit of comfortable temperature made this study to the listed set point for cooling controller $26^{\circ} \mathrm{C}$ for all zones and minimum set-point heating controller for living and bed to $18^{\circ} \mathrm{C}[33,34]$. Finally, to compensate heat losses and loads all mechanical heating cooling and ventilation systems have been absent.

Table 2. Prototypes materials description and thermal transmittance (U value)

\begin{tabular}{lccc}
\hline Characters and description & $\mathrm{U}$ value $\left(\mathrm{w} /\left(\mathrm{m}^{2} \cdot \mathrm{k}\right)\right.$ & Characters and description & $\mathrm{U}$ value $\left(\mathrm{w} /\left(\mathrm{m}^{2} \cdot \mathrm{k}\right)\right.$ \\
\hline R1 = Zinc roof & 5.88 & W4 = Straw-bales wall & $30 \mathrm{~cm}=0.14$ \\
& & & \\
& & F1 = Light weight concrete floor & 0.10 \\
R2 = Sandwich panels roof & 0.44 & Window 1 = One pane glazing & 0.85 \\
R3 = Wood + Straw + Soil (WSS) roof & 0.26 & Window 2 = Double pane glazing & 5.8 \\
W1 = Concrete blocks wall & 3.24 & Door 1 = PVC door & 2.9 \\
W2 = Cob Earth wall & $15 \mathrm{~cm}=1.86$ & & 2.0 \\
& $30 \mathrm{~cm}=1.17$ & Door 2 = Wood door & \\
W3 = Earth-bags wall & $40 \mathrm{~cm}=0.98$ & & 0.54 \\
& $30 \mathrm{~cm}=0.69$ & &
\end{tabular}


STRAW-BALE 40 AA

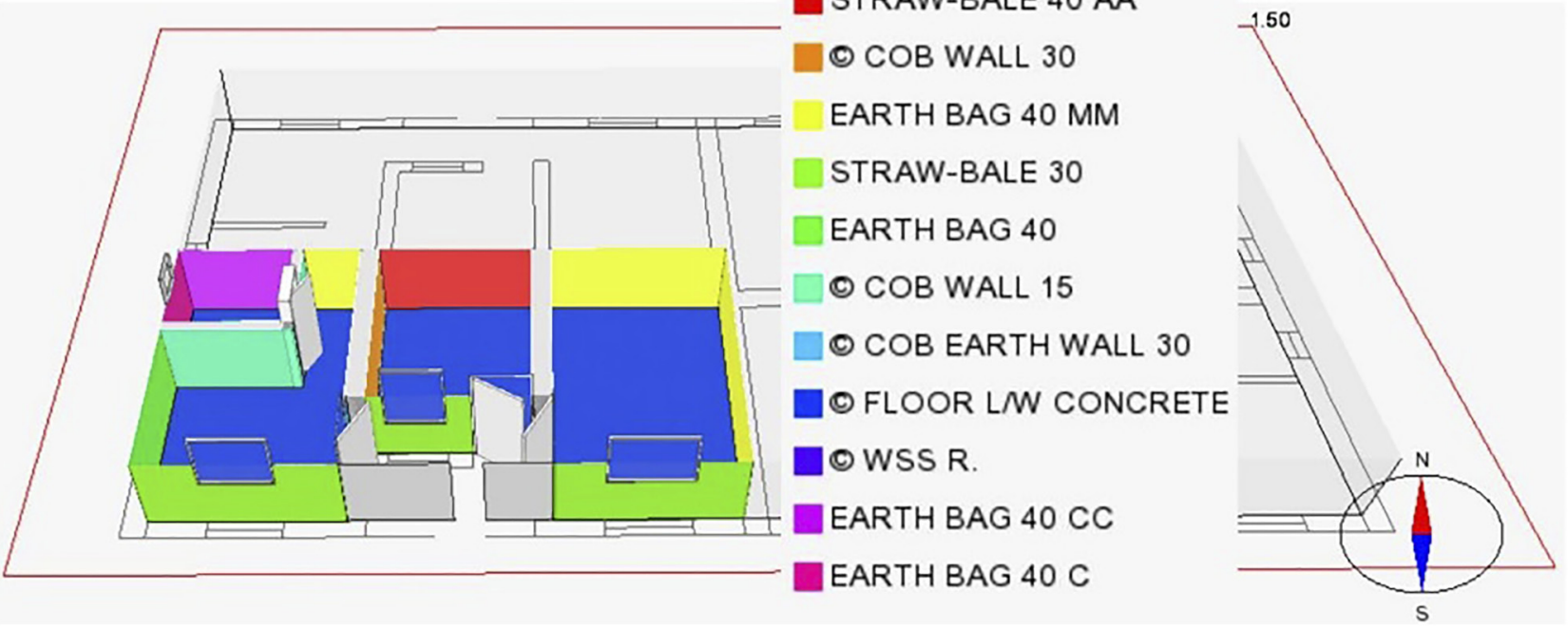

Fig. 2. Simulation model (IDA-ICE) for the targeted proposed scenario (Source: Author)

\section{RESULTS AND DISCUSSION}

\subsection{Energy assessment}

Delivered energy in the simulation tool comprises several categories for instance lighting facility, Domestic Hot Water (DHW), equipment tenant, fuel heating and electric cooling. However, to simplify the comparison of the estimated results simply fuel heating and electric cooling results have been focused and introduced, that is due to the vast similarity in the results for the other three classes Fig. 3. After estimating the performance of the first seven scenarios (S1-S7) consequently the best performed roof (WSS roof) and the best-performed wall (straw-bales wall) have been chosen for S8 while, a set of low impact materials for walls (W2, W3 and W4) with WSS roof have been selected for targeted scenario nine (S9).

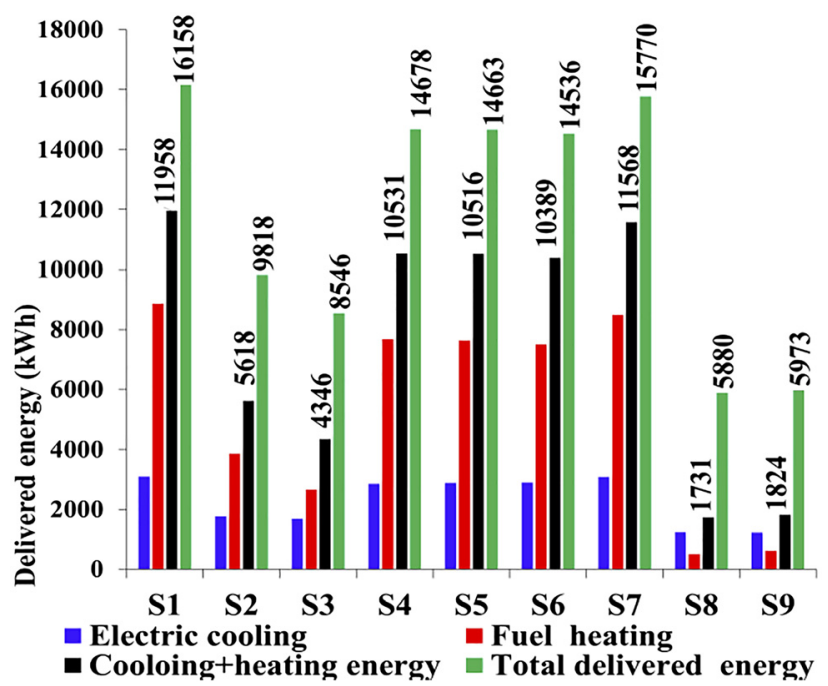

Fig. 3. Estimated delivered energy (Source: Author)
Fuel heating energy demand for the first seven scenarios is almost double or more compared to cooling energy demand conversely to the last two scenarios (S8, S9). The estimated heating energy ratio to the total heating-cooling energy for first base scenario S1 is $74 \%$, for the second base case S2 represents $68.64 \%$ while for the S8 is $28.88 \%$ and for the last scenario (S9) represents simply $33.12 \%$. Undoubtedly that is due to the high thermal insulation factor of LIC materials and specifically straw-bales material compared to other conventional materials like concrete blocks walls and zinc roof beside the good thermal mass quality of earthen materials (cob and earth-bag).

Although the total cooling and heating energy that could be saved compared to the first base case (S1) is as follow, both S2 and S3 is 53\% and 64\% respectively additionally, S4, S5 and S6 approximately the same ratio which are 12\%, 12\% and $13 \%$, respectively, however, both S8 and the targeted proposed prototype $S 9$ are about $85.5 \%$ and $85 \%$. Similarly, the same type of required energy compared to the base case two (S2) can be saved from both S8 and S9 by $69.2 \%$ and $67.5 \%$ respectively likewise, both S8 and S9 can save approximately $85 \%$ and $84.25 \%$ compared to (S7).

Furthermore regarding the total delivered energy from (heating, cooling, lighting, DHW and equipment) S9 energy demand is $5,973 \mathrm{kWh}$ annually which is approximately less than demand energy for S1 (16,158 kWh), S2 (9,818 kWh) and S7 $(15,770 \mathrm{kWh})$ by $63 \%, 39.2 \%$ and $62.1 \%$ respectively Fig. 3.

\subsection{Thermal comfort assessment}

To quantify the thermal comfort performance for all specified scenarios Table 4 accounted simply thermal comfort hours without cooling option, additionally accepted and unaccepted hours has been focused. The process concentrated on three main spaces living room with a total number of occupancy hours 8,760 , a bedroom with $4,380 \mathrm{~h}$ and a kitchen with $730 \mathrm{~h}$ annually whereas due to the big similarity for bath results in all scenarios it has not introduced. 
Table 4. Estimated thermal comfort performance (accepted and unaccepted hours)

\begin{tabular}{|c|c|c|c|c|c|c|c|}
\hline \multirow[b]{2}{*}{ Scenarios } & \multicolumn{2}{|c|}{ Living room } & \multicolumn{2}{|c|}{ Bedroom } & \multicolumn{2}{|c|}{ Kitchen } & \multirow{2}{*}{$\begin{array}{c}\text { Summation } \\
\text { accepted } \\
\text { hours }\end{array}$} \\
\hline & $\begin{array}{l}\text { Accepted } \\
\text { hours }\end{array}$ & $\begin{array}{c}\text { Un accepted } \\
\text { hours }\end{array}$ & $\begin{array}{l}\text { Accepted } \\
\text { hours }\end{array}$ & $\begin{array}{l}\text { Un accepted } \\
\text { hours }\end{array}$ & $\begin{array}{l}\text { Accepted } \\
\text { hours }\end{array}$ & $\begin{array}{l}\text { Un accepted } \\
\text { hours }\end{array}$ & \\
\hline S1 & 5,550 & 3,210 & 2,118 & 2,262 & 449 & 281 & 8,117 \\
\hline S2 & 7,784 & 976 & 3,412 & 968 & 444 & 286 & 11,640 \\
\hline S3 & 7,924 & 836 & 3,515 & 865 & 449 & 281 & 11,888 \\
\hline S4 & 5,454 & 3,306 & 1,910 & 2,470 & 437 & 293 & 7,801 \\
\hline S5 & 5,336 & 3,424 & 1,809 & 2,571 & 434 & 296 & 7,579 \\
\hline S6 & 5,231 & 3,529 & 1,664 & 2,716 & 437 & 293 & 7,332 \\
\hline S7 & 5,649 & 3,111 & 2,180 & 2,200 & 452 & 278 & 8,281 \\
\hline S8 & 7,009 & 1,751 & 4,259 & 121 & 553 & 177 & 11,821 \\
\hline S9 & 7,487 & 1,273 & 4,299 & 81 & 546 & 184 & 12,332 \\
\hline
\end{tabular}

Consequently, regarding the total occupancy hours which are $13,870 \mathrm{~h}$ for three main zones the following performance ratios have been quantified. The proposed targeted scenario (S9) is the best with the number of accepted hours 12,332 equivalent to $88.9 \%$ from annually occupancy hours while the worst scenario is S6 with 7,332 h equivalent to just $52.9 \%$. Regarding both first and second base case scenarios S1 and S2, they performed $58.5 \%$ and $83.9 \%$ respectively while S3 and S8 performed almost the same with $85.7 \%$ and $85.2 \%$ respectively. Finally, the number of accepted hours for the other three scenarios S4, S5 and S7 are 56.2\%, 54.6\% and 59.7\% respectively compared to the annual occupancy hours.

Although the number of unaccepted hours for the bestperformed scenario $S 9$ regarding thermal performance is $1,538 \mathrm{~h}$ from 13,870 annually however it is better than S1, S2 and $\mathrm{S} 7$ by $4,215,692$ and $4,051 \mathrm{~h}$ annually moreover it is better than S4, S5 and S6 by 4,531, 4,753 and 5,000 h annually. Finally, even both scenarios S3 and S8 are performed well compared to the best scenario S9 while S9 is still better than them by 444 and $511 \mathrm{~h}$ annually that is due to the good thermal mass of the materials for S9 compared to both S3 and S8.

\section{CONCLUSION}

Inspired by the issue of ongoing displacement and it is negative consequences, this paper sought to investigate and address the development of the energy and thermal performance in migrants' prototypes through the bottom-up construction method. The study used a dynamic simulation tool IDA ICE 4.8 to assess the performance of the prototypes via nine scenarios. For affordability and adaptability reasons, a few low-impact materials have been proposed for one single prototype walls as it is clear in targeted scenario nine. The assessment revealed that S8 saved $1.55 \%$ of annual delivered energy with regards to $S 9$ due to the high thermal insulation factor of straw-bales material while S9 performed better than S8 by $4.14 \%$ and $9.14 \%$ for accepted and good thermal comfort hours respectively due to the superiority high thermal mass quality of earthen materials (cob and earth-bag). The targeted scenario S9 saved $63 \%$ and $39.2 \%$ of annual delivered energy compared to base cases S1 and S2 respectively similarly, regarding the accepted hours of thermal comfort S9 performed better than S1 and S2 by $151.9 \%$ and $105.95 \%$ respectively. In conclusion, utilizing few LIC materials in one single prototype walls can serve many points like affordability, adaptability besides energy and thermal comfort performance. It is recommended for the next study to investigate the effect of typologies, morphological aspects, location and orientation on prototypes performance. The methodology of this study can be applied to various places of the world affected by migration issue.

\section{ACKNOWLEDGEMENTS}

The first author would like to thank the Ministry of Higher Education in KRI for providing the Scholarship similarly to the Stipendium Hungaricum Scholarship. Thanks to Katona Tamas for his valuable advices. He would like to thank BRHA and engineer Beiwar Nerway for providing valuable data. Furthermore, the authors appreciates the support of the János Szentágoghai Research Centre, University of Pécs, Finally, the great support of Sara Elhadad and Ali Salem has not to be forgotten for their scientific and technical help.

\section{REFERENCES}

[1] A. Heslin, N. D. Deckard, R. Oakes, and A. Montero-Colbert, "Displacement and resettlement: understanding the role of climate change in contemporary migration," in Loss and Damage from Climate Change, Climate Risk Management, Policy and Governance. R. Mechler, L. Bouwer, T. Schinko, S. Surminski, and J. Linnerooth-Bayer, Eds, Cham: Springer, 2019.

[2] Global trends 2019: forced displacement in 2019, The UN Refugee Agency (UNHCR). [Online]. Available: https://www.unhcr.org/ 5ee200e37.pdf. Accessed: Jan. 9, 2020.

[3] Internal displacement monitoring center (IDMC) 2020. [Online]. Available: https://www.internal-displacement.org/countries/iraq. Accessed: Feb. 10, 2020.

[4] "IDPs and refugees in Duhok Governorate Profile and General Information," Annual report, Board of Relief and Humanitarian Affairs, Executive Directorate, Iraqi Kurdistan, January 2018, 
[Online]. Available: https://www.brha-duhok.org/. Accessed: Oct. 10, 2019.

[5] C. R. Ray, "The Integration and Livelihood Strategies of SelfSettled refugees: The Case of Casamance Refugees in The Gambia," PhD Thesis, Coventry University, 2013.

[6] T. Scharrer, "Ambiguous citizens: Kenyan Somalis and the question of belonging, "J. East. Afr. Stud., vol. 12, no. 3, pp. 494-513, 2018.

[7] F. Dionigi, "The Syrian refugee crisis in the Kurdish region of Iraq: Explaining the role of borders in situations of forced displacement," Int. Migration, vol. 57, no. 2, pp. 10-31, 2019.

[8] M. Dabaieh, N. Emami, J. T. Heinonen, and B. Marteinsson, "A life cycle assessment of a 'minus carbon' refugee house: global warming potential and sensitivity analysis," Archnet-IJAR, vol. 14, no. 3, pp. 559-579, 2020.

[9] M. Dabaieh, and M. Andriasyan, "Vernacular rehabilitation and rebuilding for post-conflict migration and resettling," Int. Arch. Photogrammetry, Remote Sensing Spat. Inform. Sci., vol. 44, pp. 901-906, 2020.

[10] S. Elhadad, B. Baranyai, J. Gyergyák, I. Kistelegdi, and A. Salem, "Passive design strategies for residential buildings in a hot desert climate in upper Egypt," in Proceedings of the Multidisciplinary Scientific GeoConference SGEM 2019, vol. 19, Albena, Bulgaria, June 28-July 7, 2019, 2019, pp. 495-502.

[11] S. Elhadad, B. Baranyai, and J. Gyergyák, "The impact of building orientation on energy performance: A case study in new Minia, Egypt," Pollack Period., vol. 13, no. 3, pp. 31-40, 2018.

[12] R. Messaouda, S. Elhadad, and A. Boumerzoug, "Optimum window position in the building façade for high day-light performance: Empirical study in hot and dry climate," Pollack Period., vol. 15, no. 2, pp. 211-220, 2020.

[13] S. Elhadad, C. H. Radha, I. Kistelegdi, B. Baranyai, and J. Gyergyák, "Model simplification on energy and comfort simulation analysis for residential building design in hot and arid climate," Energies, vol. 13, no. 8, 2020, Paper no. 1876.

[14] D. H. Morad, "The potential and social acceptability of renewable energy sources in North Iraq: Kurdistan Region," Acad. J. Nawroz Univ., vol. 7, no. 4, pp. 93-103, 2018.

[15] H. Abdulkareem, H. Schoenefeldt, and M. Nikolopoulou, "Managing thermal comfort within the residential context of a developing region. A Field Investigation Based on Two Socioeconomically Distinct Households," in S. Roaf, N. Fergus, and W. Finlayson, Eds., 11th Windsor Conference: Resilient Comfort, London, UK, April 16-19, 2020, 2020, pp. 673-681.

[16] H. N. Zebari, and R. K. Ibrahim, "Methods and strategies for sustainable architecture in Kurdistan region, Iraq," Proced. Environ. Sci., vol. 34, pp. 202-211, 2016.

[17] R. K. Ibrahim, H. N. Zebari, and H. A. Abdulkareem. "Potential of energy conservation in residential building regulations, Kurdistan, Iraq," Proced. Environ. Sci., vol. 34, pp. 506-513, 2016.

[18] S. Halliday, Sustainable Construction. Routledge. Taylor and Frances Group, 2008.
[19] W. Weber, and S. Yannas, Eds., Lessons from Vernacular Architecture. Routledge, 2013.

[20] M. McGrath, D. Albadra, and K. Adeyeye. "Customisable shelter solutions: A case study from Zaatari refugee camp," The 5th International Conference on Architecture and Built Environment, Get it Published, p. 10, 2018.

[21] E. Wagemann, "From Shelter to Home: Flexibility in Post-disaster Accommodation," Doctoral Thesis, University of Cambridge, 2017.

[22] L. Rincón, A. Carrobé, M. Medrano, C. Solé, A. Castell, and L. Martorell, "Analysis of the thermal behavior of an Earthbag Building in Mediterranean continental climate: Monitoring and simulation," Energies, vol. 13, no. 1, 2020, Paper no. 162.

[23] S. Ibrahim, M. Ali, B. Baranyai, and I. Kistelegdi, "Simulationbased analysis of earthen heritage architecture as responsive refugee shelters (case study: Domes of Northern Syria)," Int. Arch. Photogrammetry, Remote Sensing Spat. Inform. Sci., vol. 44, pp. 365-372, 2020.

[24] F. Al Ameen, "Exploring Sustainable Strategies for Shelter Design at refugee Camps: The Case of Domiz 1 Refugee Camp in Iraq," MSc Thesis, The British University in Dubai, 2017.

[25] H. D. Mohammed, and A. A. Muhsin, "Monitoring and prediction of urban growth using GIS techniques: A case study of Duhok City Kurdistan Region of Iraq," Int. J. Sci. Eng. Res., Vol. 5, pp. 1480-1488, 2014.

[26] Köppen Climate Classification, Iraq Map of Köppen Climate Classification. 2020.

[27] I. A. Alwan, H. K. Hussein, and A. A. Nadia, "Agro-climatic zones (ACZ) using climate satellite data in Iraq Republic," IOP Conf. Ser. Mater. Sci. Eng., vol. 518, no. 2, 2019, Paper no. 022034.

[28] Demographic Survay: Kurdistan region of Iraq. Internation Organization for Immigration, Iraq Mission, 2018. [Online]. Available: https://iraq.iom.int/demographic-survey-kurdistan-region-iraq. Accessed: Jan. 8, 2020.

[29] K. Salih, "Impact of the design of urban block on buildings' indoor daylight and energy loads in semi-arid regions," in H. Bougdah, A. Versaci, A. Sotoca, F. Trapani, M. Migliore, and N. Clark, Eds, Urban and Transit Planning. Advances in Science, Technology \& Innovation, Cham: Springer. pp. 575-589, 2020.

[30] S. K. Duggal, Building Materials. Routledge, 2017.

[31] S. Cascone, R. Rapisarda, and D. Cascone, "Physical properties of straw bales as a construction material: A review," Sustainability, vol. 11, no. 12, pp. 1-19, 2019.

[32] R. Nasser, M. A. Radwan, M. A. Sadek, and H. A. Elazab, "Preparation of insulating material based on rice straw and inexpensive polymers for different roofs," Int. J. Eng. Technol., vol. 7, no. 4, pp. 1989-1994, 2018.

[33] C. Radha, Sustainable renovation of residential Buildings in Subtropical Climate Zon. PhD Thesis, University of Pecs, 2018.

[34] K. T. Salih, "Finding alternative methods for controlling the power shortage in Kurdistan through improving buildings, energy performance," Acad. J. Nawroz Univ., vol. 7, no. 3, pp. 124-132, 2018.

Open Access. This is an open-access article distributed under the terms of the Creative Commons Attribution 4.0 International License (https://creativecommons.org/ licenses/by/4.0/), which permits unrestricted use, distribution, and reproduction in any medium, provided the original author and source are credited, a link to the CC License is provided, and changes - if any - are indicated. (SID_1) 